\title{
Phenotype-genotype correlations
} among carbapenem-resistant Enterobacterales recovered from four Egyptian hospitals with the report of SPM carbapenemase

Neveen A. Abdelaziz* ${ }^{*}$

\begin{abstract}
Background: Carbapenem-resistant Enterobacterales (CRE), currently listed by the World Health Organization (WHO) as top priority critical pathogens, are a major global menace to human health. In low- and middle-income countries (LMICs) the threat is mounting fueled by selective pressures caused by antibiotic abuse and inadequate diagnostic resources.
\end{abstract}

Methods: This study phenotypically and genotypically characterized carbapenem resistance among 115 Enterobacterales isolates including 76 Klebsiella (K.) pneumoniae, 19 Escherichia (E.) coli, 14 Shigella (S.) sonnei, 5 Enterobacter (E.) cloacae, and 1 Proteus (P.) mirabilis.

Results: Ninety-three isolates (80.9\%) were carbapenem-resistant with an alarming 57.5\% carbapenem non-susceptibility in isolates collected from the outpatient department. Molecular characterization of the carbapenemases (CPases) encoding genes showed that bla $a_{\mathrm{NDM}}(80.5 \%)$ was the most prevalent; it was detected in 62 isolates (54 K. pneumoniae, 6 E. coli and 2 S. sonnei), followed by bla $a_{V I M}(36.4 \%)$ which was observed in 28 isolates (24 K. pneumoniae, 3 E. coli and 1 E. cloacae). Other CPases included bla $a_{\mathrm{KPC}}$ (28.6\%; in $20 \mathrm{~K}$. pneumoniae, 1 E. coli and $1 \mathrm{~S}$. sonnei), bla OXA-48 (26\%; in 17 K. pneumoniae, 1 E. coli, 1 E. cloacae and 1 P. mirabilis), bla $a_{\text {MP }}\left(6.5 \%\right.$; in 5 K. pneumoniae) and bla $a_{\mathrm{SPM}}$ (1.3\%; in K. pneumoniae). Notably more than half of the Enterobacterales isolates (54.5\%) co-harboured more than one CPaseencoding gene. Co-existence of bla $a_{\mathrm{NDM}}$ and bla $a_{\mathrm{VIM}}$ genes was the most dominant (31.2\%), followed by association of $b / a_{\mathrm{NDM}}$ and $b / a_{\mathrm{KPC}}(24.7 \%)$, then $b / a_{\mathrm{VIM}}$ and bla $a_{\mathrm{KPC}}(13 \%)$. Moreover, the effects of different genotypes on meropenem MIC values were assessed, and a statistically significant difference between the genotype (Ambler classes A and B) and the genotype (Ambler classes B and D) was recorded.

Conclusion: The current findings may serve for a better understanding of the context of CRE in Egypt, associated drivers and CPases.

Keywords: Carbapenemases, CRE, Correlation, Klebsiella pneumoniae, Co-existence, Bla $a_{\mathrm{NDM}}$, Surveillance

*Correspondence: neveen.abdelaziz@acu.edu.eg

Department of Microbiology and Immunology, Faculty of Pharmacy,

Ahram Canadian University, POB: 12451, Sixth of October City, Giza, Egypt

\section{Background}

Antimicrobial resistance (AMR) poses a serious global threat [1]. Over the past two decades the problem exacerbated due to the substantial increase in global antibiotic consumption [2]. Trends showed that low- and middle-income countries (LMICs), Egypt included, original author(s) and the source, provide a link to the Creative Commons licence, and indicate if changes were made. The images or other third party material in this article are included in the article's Creative Commons licence, unless indicated otherwise in a credit line to the material. If material is not included in the article's Creative Commons licence and your intended use is not permitted by statutory regulation or exceeds the permitted use, you will need to obtain permission directly from the copyright holder. To view a copy of this licence, visit http://creativecommons.org/licenses/by/4.0/. The Creative Commons Public Domain Dedication waiver (http://creativeco mmons.org/publicdomain/zero/1.0/) applies to the data made available in this article, unless otherwise stated in a credit line to the data. 
were the main consumers, with a surge in the use of "last-resort" antibiotics like carbapenems and polymyxins [3]. As a consequence, carbapenem-resistant Enterobacterales (CRE) endemic and epidemic emergence has been widely reported in hospitals $[4,5]$ and infrequently in community settings [6, 7]. Production of CPases comprises the main mechanism of carbapenem resistance in Enterobacterales. This further emphasizes the criticality of CRE, since CPases-encoding genes are typically found on mobile genetic elements (plasmids, transposons, etc.) which facilitates their dissemination [8]. Moreover, studies have shown the association of these genes with other AMR encoding genes such as extended-spectrum beta-lactamases (ESBLs), genes mediating resistance to aminoglycosides and fluoroquinolones which results in the upsurge of multidrug-resistant phenotypes [9]. Since CPasesencoding genes in Enterobacterales show wide diversity according to the geographic location, choosing the appropriate antibiotic is highly dependent upon rapid and accurate diagnostic tests. For instance, therapeutic decisions involving beta-lactamase inhibitors may fail against CPases, such as oxacillinases and metallo-betalactamases (MBLs), which necessitates identifying CPases on both the phenotypic and genomic levels [10]. Accordingly, LMICs encounter huge challenges due to scarce financial resources required for capacity building of efficient clinical laboratories to perform molecular-based tests. Relying solely on phenotypic methods to routinely report carbapenem resistance poses several challenges. First, the delay encountered to obtain the results of conventional culture-based approaches, which may force clinicians to rely on local hospital susceptibility data, as well as regional and national surveillance studies to guide their empirical treatment decisions. Besides, the obtained susceptibility patterns do not distinguish between carbapenem resistance due to carbapenemases production and that caused by other combined mechanisms such as extended spectrum beta-lactamases, AmpC and reduced permeability. As a result, carbapenems may be indicated for treatment even though a CPase is not present, hence unfavourable outcomes of potential antimicrobial resistance may arise. In Egypt, several studies were conducted to explore the prevalence of CRE strains among inpatients, nonetheless data concerning community acquired carbapenem resistance is lacking [11]. Considering all these challenges, we aimed to catch a glimpse of phenotype-genotype correlations among carbapenem-resistant Enterobacterales isolates from four Egyptian hospitals. We investigated the dissemination and the co-occurrence of CPases-encoding genes among the collected CRE isolates. Additionally, we tested the correlation between the identified genotypes and features such as the isolated organism, specimen source and department of isolation.

\section{Materials and methods}

\section{Collection of clinical isolates}

In this study, a total of 115 Enterobacterales isolates were obtained from the diagnostic microbiology laboratories of four Egyptian hospitals, namely Tanta University Hospital (TUH) $(n=47)$, National Cancer Institute (NCI) $(n=11)$, Memorial Souad Kafafi University Hospital (MSKUH) $(n=18)$, and El-Demerdash Hospital (DH) $(n=39)$ between March 2018 and September 2019. The isolates were recovered from clinical specimens, intended for routine microbiological diagnosis, collected from adult inpatients and outpatients. Only pus, blood, sputum, urine, and stool specimens were included. To avoid biased susceptibility results, we only included one Enterobacterales isolate per patient irrespective of the specimen type. Sputum and urine cultures were the major source of the recovered Enterobacterales isolates ( $47.8 \%$ and $43.5 \%$, respectively), followed by pus (4.3\%), stool (2.6\%) and blood specimens (1.7\%). Enterobacterales species were identified by traditional methods and confirmed using the MicroscanR WalkAway-96 Plus auto-identification system (Beckman Coulter, Miami, FL, USA) [12]. The collected 115 isolates included 76 (66.1\%) K. pneumoniae, 19 (16.5\%) E. coli, 14 (12.2\%) S. sonnei, 5 (4.3\%) E. cloacae, and 1 (0.9\%) P. mirabilis. The isolates were mainly from inpatients $75(65.2 \%)$ but also included outpatients 40 (34.8\%). For everyday work, the isolates were stored at $4{ }^{\circ} \mathrm{C}$ in bacterial media, and for longer storage, they were stored in glycerol stock solutions at $-70^{\circ} \mathrm{C}[13]$.

\section{Carbapenem susceptibility testing and MIC determination}

The susceptibilities of the Enterobacterales isolates to imipenem (IPM) and meropenem (MER) were determined by the disc diffusion method according to the Clinical and Laboratory Standards Institute (CLSI) guidelines [14]. The susceptibility patterns of the isolates were interpreted according to the CLSI M07-A11 protocol [15]. Isolates were considered as CRE if they were found resistant or intermediate to one or both carbapenems (IPM and MER). Micro-broth dilution method was used to determine the minimum inhibitory concentration (MIC) of meropenem (AstraZeneca, UK) according to the CLSI guidelines [14]. Negative control wells contained only culture media to ensure sterility, while positive controls were inoculated with the organism, and $E$. coli ATCC 25922 was used as a reference strain. Following a $24 \mathrm{~h}$ incubation at $37^{\circ} \mathrm{C}$, the MIC readings were 
recorded and interpreted according to the CLSI M07A11 protocol [15].

\section{PCR amplification of carbapenemases genes}

Bacterial DNA was extracted using GeneJet ${ }^{\mathrm{TM}}$ DNA extraction kit (Thermo Fisher Scientific, Waltham, MA, USA) according to the manufacturer's instructions and stored at $-20{ }^{\circ} \mathrm{C}$ for future use. PCR was performed using previously described primers (Thermo Fisher Scientific, Waltham, MA, USA) to amplify carbapenemasesencoding genes from Ambler class A: $b l a_{\mathrm{KPC}}$ [16], class B metallo-beta-lactamases (MBLs): $b l a_{\mathrm{VIM}}, b l a_{\mathrm{IMP}}, b l a_{\mathrm{SPM}}$ [17], bla $a_{\mathrm{NDM}}$ [16], and class D oxacillinases: $b l a_{\text {OXA-48- }}$ like [16]. To easily interpret the expected bands and to avoid obtaining amplification products of the same size in each PCR tube, 2 multiplex reactions were performed for the detection of the 6 genes under investigation. The first multiplex reaction involved the detection of $b l a_{\mathrm{KPC}}$, $b l a_{\mathrm{SPM}}$ and $b l a_{\mathrm{OXA}-48-\text { like, }}$ while the second involved the detection of $b l a_{\mathrm{VIM}}, b l a_{\mathrm{IMP}}$ and $b l a_{\mathrm{NDM}}$. Amplification conditions were initial denaturation at $94{ }^{\circ} \mathrm{C}$ for $5 \mathrm{~min}$; 35 cycles of denaturation at $94{ }^{\circ} \mathrm{C}$ for $30 \mathrm{~s}$, annealing at $58{ }^{\circ} \mathrm{C}$-touch-down- $52{ }^{\circ} \mathrm{C}$ for $30 \mathrm{~s}$, and elongation at $72{ }^{\circ} \mathrm{C}$ for $30 \mathrm{~s}$; then a final extension at $72{ }^{\circ} \mathrm{C}$ for $10 \mathrm{~min}$ in a TECHNE thermocycler (Bibby Scientific Ltd, Staffordshire, UK). Gel electrophoresis was carried out using the ADVANCE electrophoresis system (Mupid-exu, Tokyo, Japan) at $5 \mathrm{~V} / \mathrm{cm}$ on $1.5 \%$ agarose gel, stained with
$0.5 \mu \mathrm{g} / \mathrm{ml}$ ethidium bromide and visualized under ultraviolet light.

\section{Statistical analysis}

All analyses were carried out using R statistical platform (https://www.r-project.org) in R-studio version 1.4.1106. Several R-packages were used in data analysis and visualization including readxl, ggplot2, polycor and lares. Fisher's Exact (FE) test of independence was employed to analyze the associations between nominal variables. Moreover, the correlation between these variables was performed using the Spearman's rank correlation and strength of the association was expressed as Spearman's correlation coefficient $\left(r_{s}\right)$ between -1 and +1 . KruskalWallis (KW) test was used to compare the medians for non-normally distributed quantitative data and MannWhitney test was applied as a post-hoc test using Bonferroni correction method for multiple comparisons. For all statistical analyses, $p$-values $\leq 0.05$ were considered statistically significant.

\section{Results \\ CRE isolates}

From a total of 115 Enterobacterales isolates, 80.9\% $(n=93)$ were carbapenem-resistant and $19.1 \%(n=22)$ were susceptible. As shown in Table 1, carbapenem resistance was highly enriched in K. pneumoniae (93.4\%, $n=71)$ and $E$. coli $(57.9 \%, n=11)$ isolates (FE test

Table 1 Association between carbapenem susceptibility and different features of 115 clinical Enterobacterales isolates

\begin{tabular}{|c|c|c|c|}
\hline \multirow[t]{2}{*}{ Features } & \multirow[t]{2}{*}{ No. of isolates (\%) } & \multicolumn{2}{|c|}{ Carbapenem susceptibility } \\
\hline & & Resistant & Susceptible \\
\hline \multicolumn{4}{|l|}{ Organism } \\
\hline Klebsiella pneumoniae & $76(66.1 \%)$ & 71 & 5 \\
\hline Escherichia coli & $19(16.5 \%)$ & 11 & 8 \\
\hline Shigella sonnei & $14(12.2 \%)$ & 6 & 8 \\
\hline Enterobacter cloacae & $5(4.3 \%)$ & 4 & 1 \\
\hline Proteus mirabilis & $1(0.9 \%)$ & 1 & 0 \\
\hline \multicolumn{4}{|c|}{ Fisher's Exact test $p$-value $=0.00001$} \\
\hline \multicolumn{4}{|l|}{ Specimen } \\
\hline Sputum & $55(47.8 \%)$ & 53 & 2 \\
\hline Urine & $50(43.5 \%)$ & 33 & 17 \\
\hline Pus swab & $5(4.3 \%)$ & 5 & 0 \\
\hline Stool & $3(2.6 \%)$ & 1 & 2 \\
\hline Blood & $2(1.7 \%)$ & 1 & 1 \\
\hline \multicolumn{4}{|c|}{ Fisher's Exact test $p$-value $=0.00003$} \\
\hline \multicolumn{4}{|c|}{ Department of isolation } \\
\hline Inpatient & $75(65.2 \%)$ & 70 & 5 \\
\hline Outpatient & $40(34.8 \%)$ & 23 & 17 \\
\hline Fisher's Exact test $p$-valu & & & \\
\hline
\end{tabular}

Organisms with $<30$ isolates should be interpreted with caution, as small numbers may bias the group susceptibilities 
$p=0.00001)$. As for the fourteen S. sonnei isolates, 6 (42.9\%) were resistant to carbapenems with meropenem MICs ranging between 4 and $128 \mu \mathrm{g} / \mathrm{ml}$. While $4(80 \%)$ from five E. cloacae isolates and the $P$. mirabilis isolate were carbapenem-resistant with meropenem MICs ranging between 8 and $128 \mu \mathrm{g} / \mathrm{ml}$ (Additional file 1: Table 1S). Carbapenem-resistant isolates were obtained from the following specimens: sputum $(57 \%, n=53)$, urine $(35.5 \%$, $n=33)$, pus swab $(5.4 \%, n=5)$ and blood and stool $(1.1 \%$, $n=1$, each). Isolates from the inpatient department displayed higher frequencies of carbapenem resistance (93.3\%, $n=70 / 75)$ compared to those recovered from the outpatient department $(57.5 \%, n=23 / 40$ ) (FE test $p=0.00001$, Table 1$)$.

\section{Molecular analysis of CPase genes}

The results of multiplex PCR assays are shown in Additional file 1: Table 1S. Among the 93 carbapenem-resistant Enterobacterales isolates, $82.8 \%(n=77)$ harboured at least one or a combination of CPases-encoding genes, of these, $62(80.5 \%)$ were bla $_{\mathrm{NDM}}$ positive $(54 \mathrm{~K}$. pneumoniae, $6 \mathrm{E}$. coli and $2 \mathrm{~S}$. sonnei). Twenty-eight isolates (36.4\%) expressed bla $a_{\mathrm{VIM}}(24 \mathrm{~K}$. pneumoniae, 3 E. coli and 1 E. cloacae), while 22 isolates (28.6\%) expressed bla $_{\mathrm{KPC}}$ (20 K. pneumoniae, $1 \mathrm{E}$. coli and $1 \mathrm{~S}$. sonnei). Twenty isolates (26\%) exhibited bla $a_{\text {OXA-48 }}$ (17 K. pneumoniae, 1 E. coli, 1 E. cloacae and 1 P. mirabilis). Finally, 5 isolates (6.5\%), all $K$. pneumoniae, exhibited $b l a_{\mathrm{IMP}}$ and only one exhibited $b l a_{\mathrm{SPM}}$. For further evaluation of the identified genotypes, the isolates were clustered based on the observed number of CPases genes, and the resulting clusters were presented as a heat map (Fig. 1A). Clusters I, II, III and IV encompassed 77 isolates harbouring 4, 3,2 and 1 CPases genes, respectively. While cluster V included 38 isolates in which the tested genes were not detected. The details of the identified genotypes and the distribution among species, specimens, and department of isolation were presented in Fig. 1B. In K. pneumoniae, $b l a_{\mathrm{NDM}}$ dominated $(71.1 \%, n=54)$, followed by $b l a_{\mathrm{VIM}}$ $(31.6 \%, n=24), b l a_{\mathrm{KPC}}(26.3 \%, n=20), b l a_{\mathrm{OXA}-48}(22.4 \%$, $n=17), b l a_{\mathrm{IMP}}(6.6 \%, n=5)$ and $b l a_{\mathrm{SPM}}(1.3 \%, n=1)$. A similar trend was observed in E. coli in which genes frequencies were $b l a_{\mathrm{NDM}}(31.6 \%, n=6), b l a_{\mathrm{VIM}}(15.8 \%$, $n=3), b l a_{\mathrm{KPC}}$ and $b l a_{\mathrm{OXA}-48}(5.3 \%, n=1$, each). Of the four carbapenem-resistant $E$. cloacae isolates included in this study, only one contained CPases genes (both bla $a_{\mathrm{VIM}}$ and $\left.b l a_{\text {OXA-48 }}\right)$. Likewise, only 2 out of the 6 carbapenem-resistant $S$. sonnei exhibited CPases genes, namely $b l a_{\mathrm{NDM}}$ and $b l a_{\mathrm{KPC}}$. Finally, the P. mirabilis isolate exhibited $b l a_{\text {OXA-48 }}$ gene. Additionally, the effects of different genotypes on meropenem MICs in CPases positive isolates $(n=77)$ were assessed (Table 2). A Kruskal-Wallis test showed a statistically significant difference between the MICs against isolates with CPases-encoding genes belonging to different classes ( $p$-value $=0.005328$ ). Multiple comparisons using post-hoc Mann-Whitney test revealed a statistically significant difference between the genotype (Ambler classes $\mathrm{A}$ and $\mathrm{B}$ ) and the genotype (Ambler classes B and D) ( $p$-value $=0.000958)$. Notably, 16 isolates (5 K. pneumoniae, 4 E. coli, 4 S. sonnei and 3 E. cloacae) were phenotypically carbapenem-resistant but no CPases-encoding genes were detected.

\section{Co-existence of CPases-encoding genes}

Remarkably, 42/77 (54.5\%) Enterobacterales isolates co-harboured more than one CPase-encoding gene. In comparison to $35 / 77$ (45.5\%) ones expressing only a single gene (Fig. 2). A correlation matrix between the genes under investigation indicated that $b l a_{\mathrm{NDM}}$ displayed the strongest correlations with $b l a_{\mathrm{VIM}}$ and $b l a_{\mathrm{KPC}}\left(r_{s}=0.36\right.$ and 0.32, respectively) (Additional file 1: Fig. 1S). These results are in accordance with the recorded genotypic patterns (Fig. 2). Out of the 77 isolates harbouring CPases-encoding genes, the co-existence of $b l a_{\mathrm{NDM}}$ and bla $_{\mathrm{VIM}}$ was detected in 24 isolates $(31.2 \%)$ while expression of both $b l a_{\mathrm{NDM}}$ and $b l a_{\mathrm{KPC}}$ was recorded in 19 isolates (24.7\%). Additional statistically significant correlations $(p$-value $\leq 0.05)$ were also reported between the following gene pairs; $b l a_{\mathrm{VIM}}$ and $b l a_{\mathrm{KPC}}\left(r_{s}=0.24\right), b l a_{\mathrm{IMP}}$ and $b l a_{\mathrm{KPC}}\left(r_{s}=0.22\right), b l a_{\mathrm{OXA}-48}$ and $b l a_{\mathrm{SPM}}\left(r_{s}=0.2\right)$, $b l a_{\mathrm{NDM}}$ and $b l a_{\mathrm{IMP}}\left(r_{s}=0.2\right)$ (Additional file 1: Fig. 1S).

\section{Features associated with the carriage of CPases-encoding genes}

We explored the correlation between the detected $b l a_{\mathrm{NDM}}, b l a_{\mathrm{VIM}}, b l a_{\mathrm{KPC}}, b l a_{\mathrm{OXA}-48}$, and $b l a_{\mathrm{IMP}}$ genes and the documented features of the isolates (Fig. 3). Interestingly, bla $a_{\mathrm{NDM}}$, bla $a_{\mathrm{VIM}}$, and $b l a_{\mathrm{KPC}}$ (Fig. $3 \mathrm{~A}-\mathrm{C}$, respectively) demonstrated statistically significant $(p$-value $\leq 0.05)$ positive correlations with the same features, namely, the count of genes detected in combination, K. pneumoniae isolates from sputum cultures, and recovery from inpatients. Likewise, the count of genes detected in combination was also positively correlated with both $b l a_{\mathrm{OXA}-48}$ and $b l a_{\mathrm{IMP}}\left(r_{s}=0.316\right.$ and 0.313, respectively) (Fig. 3D, E, respectively). On the other hand, statistically significant negative correlations were obtained between certain features and the genes $b l a_{\mathrm{NDM}}$, $b l a_{\mathrm{VIM}}$, and $b l a_{\mathrm{KPC}}$. For instance, isolates from urine samples obtained from outpatients were less likely to harbour $b l a_{\mathrm{NDM}}, b l a_{\mathrm{VIM}}$, and $b l a_{\mathrm{KPC}}$ genes.

\section{Discussion}

To tackle the AMR crisis, the WHO assembly adopted a global action plan with five main objectives [18]. One goal is to strengthen the knowledge and evidence base 


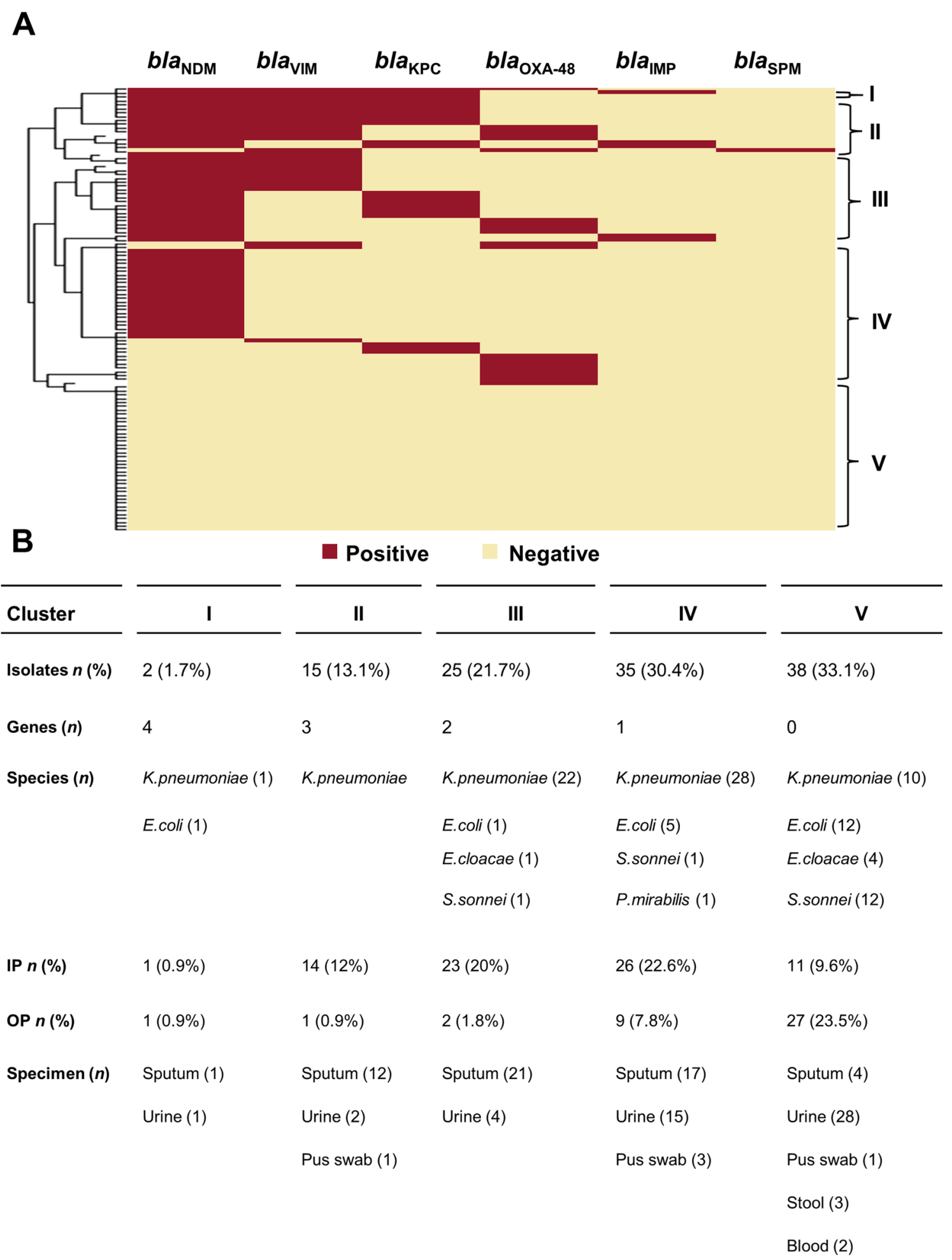

Fig. 1 Distribution of screened CPases-encoding genes among the Enterobacterales isolates. A Differentiation of 115 Enterobacterales isolates into 5 clusters based on the observed number of CPases genes as per the colours in the figure key (PCR positive gene $=$ red; $P C R$ negative gene $=$ yellow). B Tabular presentation of the characteristics of the clusters obtained in (A) showing detailed features of the identified genotypic patterns and the distribution among species, specimens, and department of isolation 
Table 2 Distribution of Enterobacterales isolates $(n=77)$ according to minimum inhibitory concentration (MIC) of meropenem with the corresponding CPases-encoding genes

\begin{tabular}{|c|c|c|c|c|c|c|c|c|c|}
\hline \multirow[t]{2}{*}{ Ambler class CPases* } & \multicolumn{8}{|c|}{ Meropenem MIC $(\mu \mathrm{g} / \mathrm{ml})$} & \multirow{2}{*}{$\begin{array}{l}\text { Median } \\
\text { MIC ( } \mu \mathrm{g} / \\
\mathrm{ml})\end{array}$} \\
\hline & 4 & 8 & 16 & 32 & 64 & 128 & $>128$ & $\mathrm{MIC}_{50}$ & \\
\hline $\begin{array}{l}\text { Class } \mathbf{A} \text { or } \mathbf{B} \\
\text { carbapenemases }\end{array}$ & 1 & - & 6 & 1 & 2 & 12 & 17 & 128 & 128 \\
\hline $\begin{array}{l}\text { Classes } \mathbf{A} \text { and } \mathbf{B} \\
\text { carbapenemases }\end{array}$ & 1 & - & - & 1 & - & 3 & 13 & $>128$ & 256 \\
\hline $\begin{array}{l}\text { Class } \mathbf{D} \\
\text { carbapenemases }\end{array}$ & - & - & 1 & 2 & 1 & 2 & 2 & 64 & 96 \\
\hline $\begin{array}{l}\text { Classes B and D } \\
\text { carbapenemases }\end{array}$ & - & 1 & 1 & 2 & 4 & 3 & 1 & 64 & 64 \\
\hline
\end{tabular}

Kruskal-Wallis test $\mathrm{H}(3)=12.7016, p=0.005328$

${ }^{*}$ Ambler class A: bla $a_{\mathrm{KPC}}$ class B: bla $a_{\mathrm{VIM}}, b l a_{\mathrm{IMP}}, b l a_{\mathrm{SPM}}, b l a_{\mathrm{NDM}}$ and class D: bla $a_{\mathrm{OXA}-48-\mathrm{like}}$

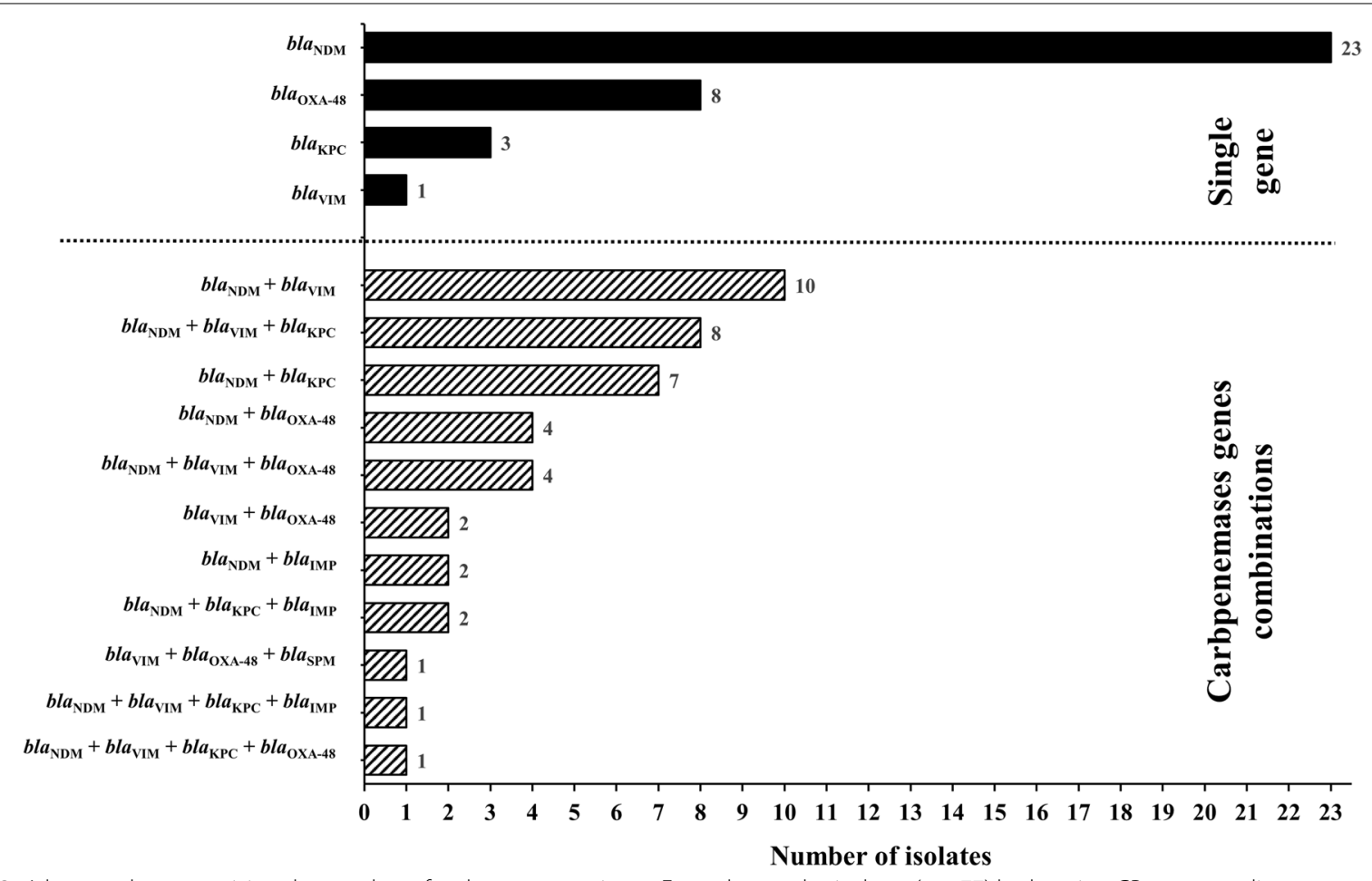

Fig. 2 A bar graph summarizing the number of carbapenem-resistant Enterobacterales isolates $(n=77)$ harbouring CPases-encoding genes (bla $a_{\mathrm{NDM}}, b / a_{\mathrm{VIM}}, b / a_{\mathrm{KPC}}, b / a_{\mathrm{OXA}-48}, b / a_{\mathrm{IMP}}$ and bla $a_{\mathrm{SPM}}$ ) either in combination (stripped bars) or as single genes (black bars)

through surveillance and research. Surveillance data can monitor the drivers of AMR and track trends across multi-sectors $[19,20]$. Consequently, interpretation of such data endorses the implementation of infection control programs [21, 22], besides guiding the choice of resistance testing methods and treatment decisions [10]. Egypt's healthcare-associated infections (HAI) surveillance system, established in 2011, is a leading prospective, standardized system in WHO's Eastern
Mediterranean Region (EMR) [23, 24]. However, limited studies have reported the increasing burden of CRE in Egypt using the system's surveillance data [5]. On the other hand, the academic network strived to provide research data to fill the knowledge gap regarding the severity of CRE problem in Egypt [11]. Routine testing for CRE resistance mechanisms is still not mandated in many clinical laboratories [25]. Consequently, they are unable to differentiate carbapenem non-susceptibility 


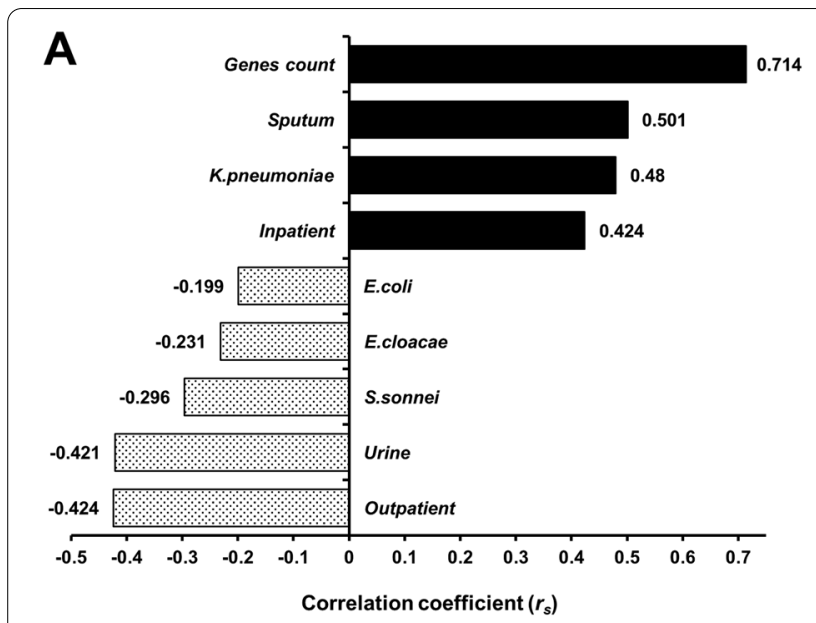

C

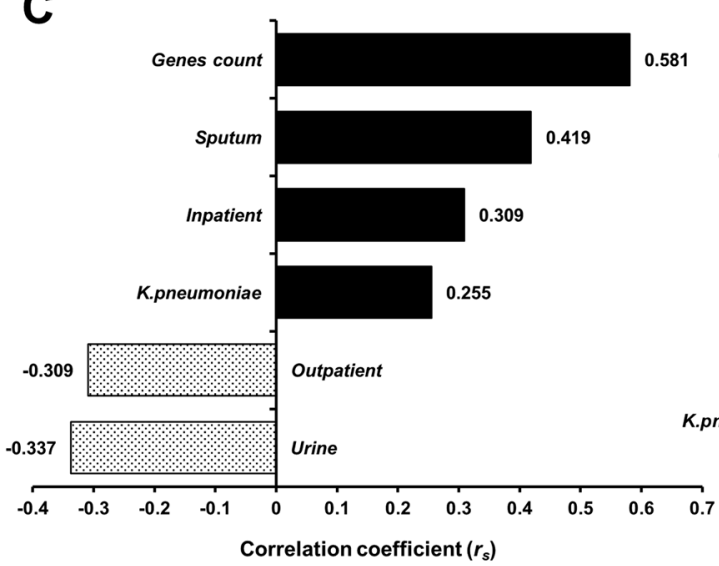

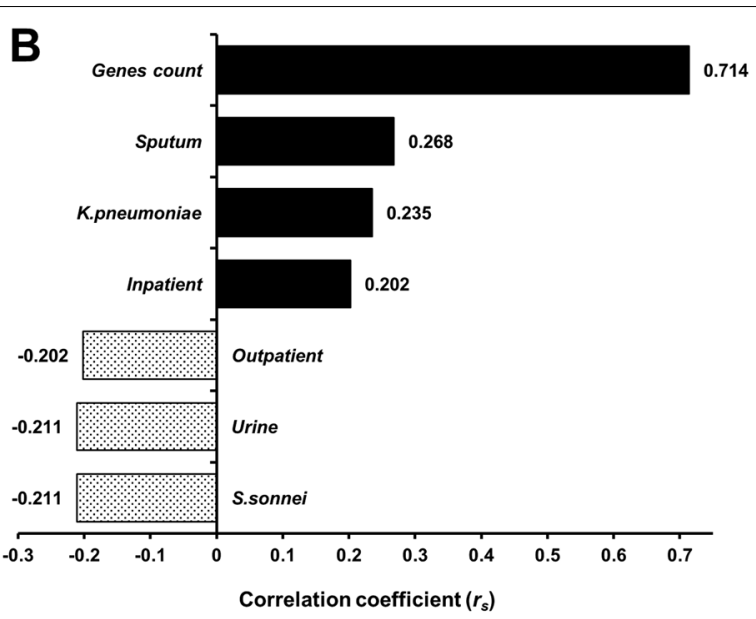

D

E

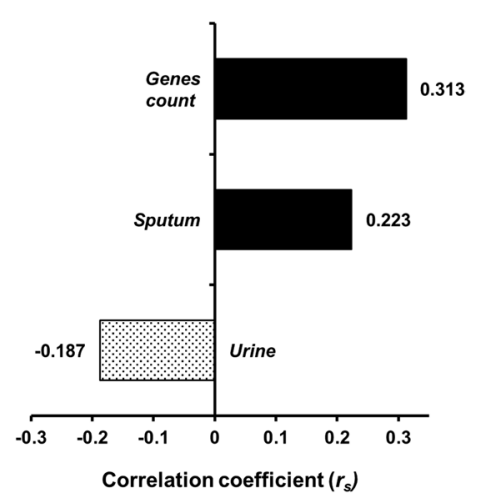

Fig. 3 Features associated with the carriage of CPases-encoding genes, namely: A bla $a_{\mathrm{NDM}} ; \mathbf{B}$ bla $a_{\mathrm{VIM}} ; \mathbf{C}$ bla $a_{\mathrm{KPC}} ; \mathbf{D}$ bla $a_{\mathrm{OXA}-48 ;}$ E bla $a_{\mathrm{IMP}}$. Only statistically significant ( $p$-value $\leq 0.05$ ) correlations were plotted. Positive correlations are designated a black colour and negative ones are dotted, and all are labelled with the corresponding Spearman's rank correlation coefficient (rs) value. The figure was generated using "corr_var" function, "lares" package (version 4.7)

caused by carbapenemases production from resistance because of other mechanisms such as overexpression of AmpC enzymes and membrane impermeability. The present study aimed to detect CPases, the most important mechanism of carbapenem resistance, among 115 Enterobacterales isolates recovered from inpatients and outpatients in 4 major Egyptian hospitals. K. pneumoniae was the most frequently recovered isolate $(66.1 \%)$, followed by E. coli (16.5\%), S. sonnei (12.2\%), E. cloacae (4.3\%) and P. mirabilis $(0.9 \%)$. In outpatients, E. coli and S. sonnei isolates dominated (43\% and $30 \%$, respectively). Strikingly, carbapenem resistance was detected in $80.9 \%$ of the Enterobacterales isolates. This level of resistance is higher than recent studies in Egypt describing the isolation of CRE with the percentages 46\% [26], 59\% [27], 68.8\% [28] from cancer patients and $48 \%$ from intensive care units [5]. In the study performed by Hassuna et al. [29], very high frequency of carbapenem resistance (95\%) was detected among the $K$. pneumoniae isolates. Comparable rates were observed in this study, in which $K$. pneumoniae cultured from sputum and pus specimens obtained from inpatients were highly enriched with carbapenem resistance $96-100 \%$. In agreement with previous studies [30] we found significant differences in carbapenem resistance between Enterobacterales isolated from inpatients compared to outpatients, which may be due to the selective pressure of excessive consumption of antibiotics in hospitals. It has been estimated that $75 \%$ of patients treated mostly for respiratory infections receive empirical carbapenem therapy [31]. Furthermore, a study involving 97,910 strains of $K$. pneumoniae found a correlation factor of $0.427(p<0.01)$ between carbapenem consumption intensity and rate of carbapenem resistance [32]. In agreement with these observations, the high carbapenem resistance rates in this study underline a pressing need for a national antimicrobial stewardship plan in Egypt 
to optimize the utilization of carbapenems as treatment options, especially in respiratory tract infections. The WHO provides a practical implementation guidance for the recommendations targeting health care facilities regarding the prevention and control of CRE, comprising how to utilize surveillance results, and put in place antibiotic stewardship programmes [33].

Next, we molecularly characterized the CPases-encoding genes in our isolates. Amid the positive genotypes, $b l a_{\mathrm{NDM}}(80.5 \%)$ was predominant, followed by $b l a_{\mathrm{VIM}}$ (36.4\%), bla $a_{\mathrm{KPC}}(28.6 \%), b l a_{\mathrm{OXA}-48}(26 \%)$ and $b l a_{\mathrm{IMP}}$ (6.5\%). Similar percentages were recently reported in Egypt $[29,34,35]$. Even though, the $b l a_{\mathrm{SPM}}$ was formerly detected in Pseudomonas aeruginosa isolates [36-38], here we report the first-time detection of the rare $b l a_{\mathrm{SPM}}$ in combination with both $b l a_{\mathrm{VIM}}$ and $b l a_{\mathrm{OXA}-48}$ from a $K$. pneumoniae isolate in Egypt. Our results uncovered substantial co-existence of CPases-encoding genes (54.5\%), this may be attributed to the fact that these genes are carried on mobile genetic elements and thus are easily transferred within different hospital settings [39]. Twenty-four isolates $(31.2 \%)$ co-harboured $b l a_{\mathrm{NDM}}$ and $b l a_{\mathrm{VIM}}$ genes. This percentage is higher than in previous studies from Egypt by Kamel et al. [26] and Khalil et al. [40] in which such association was detected in only $1(3 \%)$ and 4 (8.7\%) isolates, respectively. Whereas more current investigations reported higher rates ranging between 69\% [41] and $100 \%$ [29]. On the other hand, association of $b l a_{\mathrm{NDM}}$ and $b l a_{\mathrm{KPC}}$ was detected in 19 (24.7\%) isolates which is comparable to results by Ramadan et al., (33.3\%) [35], but higher than Ragheb et al., (5\%) [41], Khalil et al., (8.7\%) [40] and El-Kholy et al., (10\%) [38]. Additionally, $b l a_{\mathrm{VIM}}$ and $b l a_{\mathrm{KPC}}$ were simultaneously present in $10(13 \%)$ isolates, in agreement with previous reports with roughly the same incidences [40, 41]. Researchers have formerly assessed the effects of different genotypes on carbapenem MIC values [42]. Similarly, our results record a statistically significant difference between the genotype (Ambler classes A and B) and the genotype (Ambler classes B and D). This finding may be due to the low level hydrolytic activity of $b l a_{\text {OXA-48 }}$ [43]. It is noteworthy that $16(13.9 \%)$ isolates with phenotypic carbapenem-resistant profiles were negative for the tested CPases genes. In accordance with other studies [7] this may be attributed to types of carbapenemases different than those tested in this study. Besides, the presence of other combined mechanisms such as extended spectrum beta-lactamases, AmpC and reduced permeability to carbapenems caused by porin mutations [44, 45].

What is more alarming, is the excessive rates (57.5\%) of carbapenem resistance in isolates collected from the outpatient department. Even though, 10 out of the 23 non-susceptible isolates were negative for the genes used in this study, yet the resistance level conferred by the positive CPases genes (32.5\%) is worrisome. Regrettably, CRE strains could circulate in community settings and the resulting infections may easily propagate especially with the lack of proper hygiene measures [7]. Additionally, in many LMICs, including Egypt, patients can purchase antibiotics without a physician's prescription [46]. In a recent study conducted among 563 Egyptian medical students, about $77.7 \%$ of the participants were self-medicated [47].

A major goal of this study was to detect features associated with carriage of CPases-encoding genes. Successful strategies for preventing the transmission of these problematic strains require thorough and meaningful characterization of these infections in respect to causative organism, department of isolation and specimen source. Such approach may prompt the improvement of the applied infection control measures, provide guidelines for effective empiric therapy, and regulate the use of novel combinations involving beta-lactamase inhibitors. In agreement with previous studies [10], $b l a_{\mathrm{NDM}}$ and $b l a_{\mathrm{KPC}}$ were strongly correlated to K. pneumoniae isolated from sputum cultures recovered from inpatients. Correspondingly, improved infection control regimens are needed, primarily with patients suffering from respiratory tract infections caused by $K$. pneumoniae. A recent study highlighted the association between contamination of hospital's environment and transmission of carbapenemresistant $K$. pneumoniae in ICUs [48]. Furthermore, long term carriage of $b l a_{\mathrm{KPC}}$, for up to 3 years, was defined in patients discharged from a hospital with an outbreak of KPC producing K. pneumoniae [49]. Of note, all the investigated CPases-encoding genes, except $b l a_{\mathrm{SPM}}$, were significantly associated with the overall count of genes detected in combination. This implies the high likelihood of the co-existence of the investigated CPases-encoding genes which raises deep concerns about the simultaneous transmission of such genes.

Even though sample-based surveillance enabled us to report the most frequent types of infections caused by CRE, however this study had some limitations. First, the number of clinical isolates was small. Hence, it was insufficient to draw firm conclusions about the true resistance rates except for K. pneumoniae [50]. Second, isolates were obtained anonymously from the microbiology laboratories, so no data were available on the patient's microbiological history and prior antibiotic use. Finally, with respect to outpatients, a common practice in Egypt is to seek antimicrobials without being tested for susceptibility, thus the examined isolates are more likely to be from patients who have failed first line and even second line treatments, which might have caused an overestimation of the resistance rates in this study. 


\section{Conclusion}

This study underlines the escalating dilemma of CRE prevalence in Egyptian hospitals and sheds the light on the rising incidences in community settings. Here we elucidated the prevalent CPases-encoding genes present either in combination or as single genes. To address this challenge, ongoing identification, and riskbased surveillance of CRE are indispensable. Equally crucial is the urgent implementation of a national antimicrobial stewardship plan, to diminish the current burden of CRE in Egyptian hospitals and circumvent its emergence in community settings.

\begin{abstract}
Abbreviations
LMICs: Low- and middle-income countries; CRE: Carbapenem-resistant Enterobacterales; CPase: Carbapenemase; AMR: Antimicrobial resistance; ESBLs: Extended-spectrum beta-lactamases; MBLs: Metallo- beta-lactamases; IPM: Imipenem; MER: Meropenem; FE test: Fisher's Exact test; KW test: KruskalWallis test; IP: Inpatient; OP: Outpatient; WHO: World Health Organization; HAl: Healthcare-associated infection; EMR: Eastern Mediterranean Region; TUH: Tanta University Hospital; NCI: National Cancer Institute; MSKUH: Memorial Souad Kafafi University Hospital; DH: El-Demerdash Hospital; CLSI: Clinical Laboratory Standard Institute.
\end{abstract}

\section{Supplementary Information}

The online version contains supplementary material available at https://doi. org/10.1186/s13756-022-01061-7.

Additional file 1. Results of carbapenem susceptibility, multiplex PCR and correlations between CPases.

\section{Acknowledgements}

The author hereby acknowledges Department of Microbiology and Immunology, Faculty of Pharmacy, Ahram Canadian University (ACU) for providing the facilities and support required to perform the practical work.

\section{Authors' contributions}

NA was responsible for the design of the study, acquisition of data, conducting the experimental work, analysis of data, writing the article and final approval of manuscript.

\section{Funding}

This research did not receive any specific grant from funding agencies in the public, commercial, or not-for-profit sectors.

\section{Availability of data and materials}

All data generated or analysed during this study are included in this published article and supplementary file.

\section{Declarations}

\section{Ethics approval and consent to participate}

All experiments and study protocols complied with relevant guidelines, regulations, and standards of the ethical committee of Faculty of Pharmacy, Ahram Canadian University, and international ethical guidelines for biomedical research. The collected CRE isolates were obtained from routine laboratory specimens in the four hospitals, thus there was no direct or indirect contact with any patient and consequently no informed consent was required.

\section{Consent for publication}

Not applicable.

\section{Competing interests}

The authors declare that they have no competing interests.

Received: 14 September 2021 Accepted: 11 January 2022

Published online: 21 January 2022

\section{References}

1. Ramadan AA, Abdelaziz NA, Amin MA, Aziz RK. Novel blaCTX-M variants and genotype-phenotype correlations among clinical isolates of extended spectrum beta lactamase-producing Escherichia coli. Sci Rep. 2019:9:4224. https://doi.org/10.1038/s41598-019-39730-0.

2. Klein EY, Van Boeckel TP, Martinez EM, Pant S, Gandra S, Levin SA, et al. Global increase and geographic convergence in antibiotic consumption between 2000 and 2015. Proc Natl Acad Sci. 2018;115:E3463-70.

3. Lynch III JP, Clark NM, Zhanel GG. Escalating antimicrobial resistance among enterobacteriaceae: focus on Carbapenemases. Expert Opin Pharmacother 2021.

4. Logan LK, Weinstein RA. The epidemiology of carbapenem-resistant enterobacteriaceae: the impact and evolution of a global menace. J Infect Dis. 2017;215:S28-36. https://doi.org/10.1093/infdis/jiw282.

5. Kotb S, Lyman M, Ismail G, Abd El Fattah M, Girgis SA, Etman A, et al. Epidemiology of carbapenem-resistant Enterobacteriaceae in Egyptian intensive care units using National Healthcare-associated Infections Surveillance Data, 2011-2017. Antimicrob Resist Infect Control 2020;9:1-9.

6. Nordmann P, Couard J-P, Sansot D, Poirel L. Emergence of an autochthonous and community-acquired NDM-1-producing Klebsiella pneumoniae in Europe. Clin Infect Dis. 2012;54:150-1.

7. Pan F, Tian D, Wang B, Zhao W, Qin H, Zhang T, et al. Fecal carriage and molecular epidemiology of carbapenem-resistant Enterobacteriaceae from outpatient children in Shanghai. BMC Infect Dis. 2019;19:1-6.

8. Loqman S, Soraa N, Diene SM, Rolain J-M. Dissemination of Carbapenemases (OXA-48, NDM and VIM) Producing Enterobacteriaceae Isolated from the Mohamed VI University Hospital in Marrakech. Morocco Antibiotics. 2021;10:492.

9. Meletis G. Carbapenem resistance: overview of the problem and future perspectives. Ther Adv Infect Dis. 2016;3:15-21. https://doi.org/10.1177/ 2049936115621709.

10. Nordmann P, Poirel L. Epidemiology and diagnostics of carbapenem resistance in gram-negative bacteria. Clin Infect Dis. 2019;69:S521-8.

11. El-Kholy A, El-Mahallawy HA, Elsharnouby N, Aziz MA, Helmy AM, Kotb $R$. Landscape of multidrug-resistant gram-negative infections in Egypt: survey and literature review. Infect Drug Resist. 2021;14:1905.

12. Snyder J, Munier G, Johnson C. Direct comparison of the BD phoenix system with the MicroScan WalkAway system for identification and antimicrobial susceptibility testing of Enterobacteriaceae and nonfermentative gram-negative organisms. J Clin Microbiol. 2008;46:2327-33.

13. Abdel-Baky RM, Ali MA, Abuo-Rahma GE-DAA, AbdelAziz N. Inhibition of urease enzyme production and some other virulence factors expression in Proteus mirabilis by $\mathrm{N}$-acetyl cysteine and dipropyl disulphide. In: Donelli G, editor. Advances in microbiology, infectious diseases and public health: Volume 7. Cham: Springer International Publishing; 2017. p. 99-113.

14. CLSI. Methods for dilution antimicrobial susceptibility tests for bacteria that grow aerobically, 11th Edition (M07-Ed11); Clinical and Laboratory Standards Institute: Wayne, PA, USA. 2018.

15. CLSI. Performance Standards for Antimicrobial Susceptibility Testing; Twenty-Ninth Informational Supplement (M100-S29); Clinical and Laboratory Standards Institute: Wayne, PA, USA. 2019.

16. Poirel L, Walsh TR, Cuvillier V, Nordmann P. Multiplex PCR for detection of acquired carbapenemase genes. Diagn Microbiol Infect Dis. 2011;70:11923. https://doi.org/10.1016/j.diagmicrobio.2010.12.002.

17. Ellington MJ, Kistler J, Livermore DM, Woodford N. Multiplex PCR for rapid detection of genes encoding acquired metallo-beta-lactamases. J Antimicrob Chemother. 2007;59:321-2. https://doi.org/10.1093/jac/dkl481.

18. World Health O. Global action plan on antimicrobial resistance. Geneva: World Health Organization; 2015. p. 2015.

19. Peacock S, Ashley E, Shetty N, Patel J. Harnessing alternative sources of antimicrobial resistance data to support surveillance in low-resource settings. 2019. 
20. Gandra S, Alvarez-Uria G, Turner P, Joshi J, Limmathurotsakul D, van Doorn $H R$. Antimicrobial resistance surveillance in low-and middle-income countries: progress and challenges in eight South Asian and Southeast Asian countries. Clin Microbiol Rev. 2020;33:e00048-e119.

21. El-Kholy AA, Girgis SA, Shetta MA, Abdel-Hamid DH, Elmanakhly AR. Molecular characterization of multidrug-resistant Gram-negative pathogens in three tertiary hospitals in Cairo, Egypt. Eur J Clin Microbiol Infect Dis 2020:1-6.

22. Jayatilleke K. Challenges in implementing surveillance tools of highincome countries (HICS) in low middle income countries (LMICS). Curr Treat Opt Infect Dis 2020:1-11.

23. See I, Lessa FC, ElAta OA, Hafez S, Samy K, El-Kholy A, et al. Incidence and pathogen distribution of healthcare-associated infections in pilot hospitals in Egypt. Infect Control Hosp Epidemiol. 2013;34:1281-8.

24. Talaat M, El-Shokry M, El-Kholy J, Ismail G, Kotb S, Hafez S, et al. National surveillance of health care-associated infections in Egypt: developing a sustainable program in a resource-limited country. Am J Infect Control. 2016:44:1296-301.

25. Singh-Moodley A, Perovic O. Antimicrobial susceptibility testing in predicting the presence of carbapenemase genes in Enterobacteriaceae in South Africa. BMC Infect Dis. 2016;16:1-10

26. Kamel NA, El-tayeb WN, El-Ansary MR, Mansour MT, Aboshanab KM. Phenotypic screening and molecular characterization of carbapenemaseproducing Gram-negative bacilli recovered from febrile neutropenic pediatric cancer patients in Egypt. PLoS ONE. 2018;13: e0202119. https:// doi.org/10.1371/journal.pone.0202119.

27. Osama D, El-Mahallawy H, Mansour MT, Hashem A, Attia AS. Molecular characterization of carbapenemase-producing Klebsiella pneumoniae isolated from Egyptian pediatric cancer patients including a strain with a rare gene-combination of $\beta$-lactamases. Infect Drug Resist. 2021;14:335.

28. Tawfick MM, Alshareef WA, Bendary HA, Elmahalawy H, Abdulall AK. The emergence of carbapenemase bla NDM genotype among carbapenemresistant Enterobacteriaceae isolates from Egyptian cancer patients. European J Clin Microbiol Infect Dis 2020:1-9.

29. Hassuna NA, AbdelAziz RA, Zakaria A, Abdelhakeem M. Extensively-drug resistant Klebsiella pneumoniae recovered from neonatal sepsis cases from a major NICU in Egypt. Front Microbiol. 2020. https://doi.org/10. 3389/fmicb.2020.01375

30. Saperston KN, Shapiro DJ, Hersh AL, Copp HL. A comparison of inpatient versus outpatient resistance patterns of pediatric urinary tract infection. J Urol. 2014;191:1608-13.

31. Wagner JL, Rhodes NJ, Scheetz MH, Bosso JA, Goff DA, Rybak MJ, et al. Opportunities for antimicrobial stewardship among carbapenemtreated patients in 18 North American hospitals. Int J Antimicrob Agents. 2020;55:105970

32. Yang $P$, Chen $Y$, Jiang $S$, Shen $P, L$ Lu X, Xiao Y. Association between antibiotic consumption and the rate of carbapenem-resistant Gram-negative bacteria from China based on 153 tertiary hospitals data in 2014. Antimicrob Resist Infect Control. 2018;7:1-7.

33. World Health O. Guidelines for the prevention and control of carbapenem-resistant Enterobacteriaceae, Acinetobacter baumannii and Pseudomonas aeruginosa in health care facilities. Geneva: World Health Organization; 2017. p. 2017.

34. Ghaith DM, Zafer MM, Said HM, Elanwary S, Elsaban S, Al-Agamy MH, et al. Genetic diversity of carbapenem-resistant Klebsiella pneumoniae causing neonatal sepsis in intensive care unit, Cairo, Egypt. Eur J Clin Microbiol Infect Dis. 2020;39:583-91.

35. Ramadan Mohamed E, Ali MY, Waly NG, Halby HM, El-Baky A, Mahmoud R. The Inc FIl plasmid and its contribution in the transmission of blaNDM-1 and blaKPC-2 in Klebsiella pneumoniae in Egypt. Antibiotics. 2019;8:266.

36. Hashem H, Hanora A, Abdalla S, Shaeky A, Saad A. Dissemination of metallo- $\beta$-lactamase in Pseudomonas aeruginosa isolates in Egypt: mutation in blaVIM-4. APMIS: acta pathologica, microbiologica, et immunologica Scandinavica. 2017;125:499-505. https://doi.org/10.1111/apm.12669.

37. Abaza AF, El Shazly SA, Selim HSA, Aly GSA. Metallo-Beta-Lactamase Producing Pseudomonas aeruginosa in a Healthcare Setting in Alexandria, Egypt. Pol J Microbiol. 2017;66:297-308. https://doi.org/10.5604/01.3001. 0010.4855 .

38. El-Kholy AA, Elanany MG, Sherif MM, Gad MA. High prevalence of VIM, $\mathrm{KPC}$, and NDM expression among surgical site infection pathogens in patients having emergency surgery. Surg Infect. 2018;19:629-33.
39. El-Badawy MF, El-Far SW, Althobaiti SS, Abou-Elazm Fl, Shohayeb MM. The first Egyptian report showing the co-existence of blaNDM-25, blaOXA-23, blaOXA-181, and blaGES-1 among Carbapenem-resistant K pneumoniae Clinical Isolates Genotyped by BOX-PCR. Infect Drug Resist. 2020;13:1237.

40. Khalil MA, Elgaml A, El-Mowafy M. Emergence of multidrug-resistant New Delhi metallo- $\beta$-lactamase-1-producing Klebsiella pneumoniae in Egypt. Microb Drug Resist. 2017;23:480-7.

41. Ragheb SM, Tawfick MM, El-Kholy AA, Abdulall AK. Phenotypic and genotypic features of klebsiella pneumoniae harboring carbapenemases in Egypt: OXA-48-like carbapenemases as an investigated model. Antibiotics. 2020;9:852

42. Sherif MM, Elkhatib WF, Khalaf WS, Elleboudy NS, Abdelaziz NA. Multidrug Resistant Acinetobacter baumannii Biofilms: Evaluation of PhenotypicGenotypic Association and Susceptibility to Cinnamic and Gallic Acids. Frontiers in microbiology 2021;12.

43. Mairi A, Pantel A, Sotto A, Lavigne J-P, Touati A. OXA-48-like carbapenemases producing Enterobacteriaceae in different niches. Eur $\mathrm{J}$ Clin Microbiol Infect Dis. 2018;37:587-604. https://doi.org/10.1007/ s10096-017-3112-7.

44. Suay-García B, Pérez-Gracia MT. Present and future of Carbapenem-resistant Enterobacteriaceae (CRE) Infections. Antibiotics (Basel). 2019;8:122. https://doi.org/10.3390/antibiotics8030122.

45. Annavajhala MK, Gomez-Simmonds A, Uhlemann A-C. Multidrugresistant Enterobacter cloacae complex emerging as a global Diversifying Threat. Front Microbiol. 2019. https://doi.org/10.3389/fmicb.2019.00044.

46. Dooling KL, Kandeel A, Hicks LA, El-Shoubary W, Fawzi K, Kandeel Y, et al. Understanding antibiotic use in Minya District, Egypt: physician and pharmacist prescribing and the factors influencing their practices. Antibiotics (Basel). 2014;3:233-43. https://doi.org/10.3390/antibiotics3020233.

47. Elden NMK, Nasser HA, Alli A, Mahmoud N, Shawky MA, Ibrahim AAEA, et al. Risk factors of antibiotics self-medication practices among University Students in Cairo, Egypt. Open Access Macedonian J Med Sci. 2020;8:7-12. https://doi.org/10.3889/oamjms.2020.3323.

48. Yan Z, Zhou Y, Du M, Bai Y, Liu B, Gong M, et al. Prospective investigation of carbapenem-resistant Klebsiella pneumonia transmission among the staff, environment and patients in five major intensive care units, Beijing. J Hosp Infect. 2019;101:150-7.

49. Lübbert C, Lippmann N, Busch T, Kaisers UX, Ducomble T, Eckmanns T, et al. Long-term carriage of Klebsiella pneumoniae carbapenemase-2-producing Kpneumoniae after a large single-center outbreak in Germany. Am J Infect Control. 2014;42:376-80.

50. CLSI. Analysis and presentation of cumulative antimicrobial susceptibility test data, 4th Edition (M39-A4); Clinical and Laboratory Standards Institute: Wayne, PA, USA. 2014.

\section{Publisher's Note}

Springer Nature remains neutral with regard to jurisdictional claims in published maps and institutional affiliations.

$$
\begin{aligned}
& \text { Ready to submit your research? Choose BMC and benefit from: } \\
& \text { - fast, convenient online submission } \\
& \text { - thorough peer review by experienced researchers in your field } \\
& \text { - rapid publication on acceptance } \\
& \text { - support for research data, including large and complex data types } \\
& \text { - gold Open Access which fosters wider collaboration and increased citations } \\
& \text { - maximum visibility for your research: over } 100 \mathrm{M} \text { website views per year }
\end{aligned}
$$

\section{At $\mathrm{BMC}$, research is always in progress.}

Learn more biomedcentral.com/submissions 